\title{
HUBUNGAN ANTARA PENGETAHUAN DENGAN SIKAP IBU USIA 40 - 45 TAHUN TERHADAP MENOPAUSE DI RW O4 SUKA MULYA WILAYAH KERJA PUSKESMAS SAIL PEKANBARU TAHUN 2009
}

\author{
Riamah \\ Dosen Akper Dharma Husada Pekanbaru \\ Email: riariamah@yahoo.com
}

\begin{abstract}
Menopause is the permanent cessation of menstruation in a woman who generally occurs at age 50-51 years. Causes that trigger menopause is a disease such as tuberculosis of the ovary or ovarian cancer, lifestyle is wrong, the shift in eating patterns in some women, lazy to exercise, excessive exercise. This study is a correlational design approach croos sectional study aimed to examine the relationship between knowledge with maternal attitude toward menopause. The study population was 50 mothers aged 40-45 years, using total sampling method. Measuring instrument used was a questionnaire. From the results of the data collection characteristics of the respondents found the majority of respondents was 40 years old (46\%), education level of the majority of high school educated are (46\%), work as respondents (66\%) did not work, whereas for information as much (66\%) of respondents had get information and most received resources from books / magazines as many (28\%). The analysis is Univariate and Bivariate. In this study as many (66\%) of respondents have a high knowledge level (median = 8) and as many (58\%) of mothers have a positive attitude (median $=45$ ). The results of this study indicate that there is no relationship between the level of knowledge of the mother's attitude toward menopause where $\rho=0: 41>\alpha=0.05$. This means that women who have high knowledge about menopause does not affect the mother's attitude to be positive as well as negative because of the difference between high and low knowledge that has positive and negative attitudes not too siqnifikan.
\end{abstract}

Keywords: Knowledge, Attitude, Menopause.

\section{PENDAHULUAN}

Keberhasilan pembangunan termasuk pembangunan kesehatan telah meningkatkan status kesehatan dan gizi masyarakat antara lain meningkatnya umur harapan hidup (UHH). Pada tahun 1971 UHH penduduk Indonesia adalah 46,5 tahun dan pada tahun 2005 di perkirakan mencapai 68,2 tahun, dan terjadi pergesaran umur menopause dari umur 46 tahun pada tahun 1980 menjadi 49 tahun pada tahun 2000. Lebih lanjut di tegaskan, berdasarkan perhitungan statistik, di perkirakan di tahun 2020 jumlah penduduk Indonesia akan mencapai 262,6 juta jiwa dengan jumlah perempuan yang hidup dalam usia menopause adalah 30,3 juta jiwa dari jumlah laki-laki, diusia andropause akan mencapai 24,7 juta. Jumlah wanita mulai usia 50 tahun keatas mengalami menopause pada tahun 2000 sebanyak 15,5 juta orang atau 7,6 \% dari penduduk. Pada tahun 2020 di estimikasikan 30,2 juta orang atau $11,5 \%$ dari jumlah penduduk Indonesia wanita yang mengalami menopause pada usia 50 tahun keatas (Depkes RI,2005).

Wanita usia 40-45 tahun disebut dengan wanita usia pra-menopause yang merupakan masa peralihan dari periode reproduksi keperiode non reproduksi. Keluhan, gejala, penyebab, komplikasi, pencegahan dan penanganan yang dilakukan wanita memasuki usia menopause, dipengaruhi oleh tingkat pengetahuan wanita tentang menopause (Antantri, 2005).

Pre-menopause adalah kondisi fiologis pada wanita yang telah memasuki proses penuan (eging) yang ditandai dengan menurunnya kadar hormon estrogen. Premenopause sering menimpa wanita yang berusia menjelanh 40 tahun ke atas (Purnobasuki, 2004). Menopause adalah kehidupan yang normal yang terjadi pada kehidupan seorang wanita dan sudah mencapai menopause apabila tidak mendapatkan mentruasi selama 12 bulan secara berurutan, dan tidak ada penyebab lain untuk perubahan yang terjadi selama menopause yang umumnya terjadi 
pada usia 45-55 tahun. Produksi hormone estrogen dan progesterone pada seorang wanita secara perlahan berkurang sehingga terjadi berbagai gejala (Depkes, 2008).

Penjelasan tentang penyebab menopause dimana terjadi kerusakan pada produksi indung telur, estrogen tidak ada lagi atau menurun merupakan hal yang tidak sebenarnya. Indung telur perempuan tidak rusak pada saat menopause, hanya mengikuti degenerasi atau penuaan secara ilmiah. Begitu juga dengan hormone estrogen tidak berhenti diproduksi di dalam tubuh, tapi produksi sudah mulai berkurang secara berangsur-angsur bahkan sejak perempuan memasuki usia tiga puluhan. (Irawati, 2007).

Gejala menopause berbeda-beda pada setiap orang. Gejala menopause dapat berupa insomnia, rasa panas, banyak berkeringat, berkurangnya daya ingat dan sulit menahan dorongan untuk kencing (Irawati, 2007). Kadar hormone estrogen yang rendah di dalam tubuh akan membuat perempuan mengalami keluhan atau gejala ringan diawal masa menopause. Hal yang dirasakan perempuan di awal masa menopause adalah, sakit kepala, mudah pingsan, depresi, nyeri tulang dan sendi, daya ingat menurun, sulit konsentrasi. Rasa panas pada malam hari merupakan gejala pramenopause paling umum terjadi yaitu sekitar 70 hingga $80 \%$ dari semua wanita. Rasa panas menyebabkan wanita pra- menopause berkeringat pada malam hari yang biasanya terjadi pada pukul 3 sampai 4 pagi, rasa ini membuat tidur tidak nyaman (Rahayu, 2007). Secara normal wanita akan mengalami menopause antara usia 40-50 tahun. Pada saat menopause, wanita akan mengalami perubahanperubahan didalam organ tubuhnya yang disebabkan oleh bertambahnya usia.

Dari hari kehari usia akan terus berjalan dan setiap orang seiring dengan bertambahnya usia tidak akan lepas dari predikat tua. Dengan bertambahnya usia gerak-gerik, tingkah laku, cara berpakaian dan bentuk tubuh mengalami suatu perubahan. Penyusuian fisik yang paling berat yang harus dialami oleh orang yang beranjak tua adalah adanya perubahan- perubahan pada kemampuan seksual mereka. Pada wanita, mereka akan memasuki masa menopause. Menopause/ berhentinya periode menstruasi pada wanita adalah salah satu tanda penuaan, umumnya terjadi pada usia 50-51 tahun. Namun sebelum mentruasi benar-benar berhenti, proses tersebut didahului dengan ketidakteraturan siklus menstruasi (Kesrespro, 2007).

Adapun salah satu upaya yang dilakukan dalam menghadapi masalah- masalah menopause adalah dengan memahami tentang masalah yang terjadi seputar menopause. Adanya pengetahuan yang tepat diharapkan dapat melakukan pencegahan secara dini dalam memasuki masa menopause tanpa harus mengalami keluhan-keluhan yang seharusnya terjadi dan diharapkan dapat meningkatkan derajat kesehatan. Sikap positif bisa muncul jika diimbangi informasi dan pengetahuan yang cukup, serta kesiapan fisik, mental dan spiritual yang mantap. Sehingga saat memasuki masa menopause ini telah mengetahui betul tandatanda yang akan di alaminya. Ada kaitan antara pengetahuan dengan sikap seseorang. Jika pengetahuan baik maka akan mempengaruhi sikap dan tindakan seseorang untuk menjadi baik(Azwar, 2002).

Menjadi tua seringkali hal yang menakutkan wanita. Kekhawatiran akan hal ini berawal dari pemikiran bahwa dirinya akan menjadi tidak sehat, tidak bugar, dan tidak cantik lagi. Padahal masa menopause merupakan salah satu fase penting yang harus dijalani seorang wanita dalam kehidupannya.Wanita menopause akan mengalami berbagai fungsi tubuh yang menurun sehingga akan berdampak pada ketidaknyamaan. Keluhan tersebut dapat disikapi berbeda oleh setiap wanita. Apabila wanita berpikir positif maka berbagai keluhan dapat dilalui dengan lebih mudah. Namun sebaliknya, apabila wanita tersebut berpikir negatif maka keluhan- keluhan yang muncul semakin memberatkan dan menekan hidupnya (Kasdu, 2002). Berdasarkan data yang diperoleh dari kelurahan Suka Mulya, RW 04 mempunyai Ibu Pre-menopausenya yang berusia $40 \quad-45$ tahun berjumlah 50 orang.Berdasarkan hasil wawancara dengan 
beberapa Ibu di RW 04 dengan 10 orang ibu berusia 40-45 tahun $60 \%$ yang tidak mengetahui tentang menopause. Berdasarkan data diatas peneliti tertarik untuk meneliti “ Hubungan Antara Pengetahuan Dengan Sikap Ibu Umur 40- 45 tahun Terhadap Menopause Di RW 04 Suka Mulya Di Wialyah Kerja puskesmas Sail Pekanbaru pada tahun 2009“.

\section{METODOLOGI PENELITIAN}

Desain penelitian ini adalah keseluruhan dari perencanaan untuk menjawab pertanyaan penelitian dan mengantisipasi beberapa kesulitan yang mungkin timbul selama proses penelitian. Desaian penelitian ini menggunakan desaian korelasional dengan menggunakan pendekatan study cross sectoinal. Pada studi cross sectional dimana subjek diobservasi satu kali saja melalui pengukuran atau pengamatan pada saat yang bersamaan dengan tujuan untuk melihat variable bebas (independent) dan variable terikat (dependent) yang dilakukan pada saat pengolahan data

Populasi dalam penelitian ini adalah keseluruhan objek penelitian atau objek yang di teliti (Notoatmodjo,2005). Populasi dalam penelitian ini adalah seluruh ibu usia 40-45 tahun di RW 04 Suka Mulya wilayah kerja Puskesmas Sail Pekanbaru dengan jumlah 50 Orang.

Instrument yang digunakan pada penelitian ini berupa: pertanyaan pengetahuan ibu tentang menopause dalam bentuk jawaban Benar (B) Salah (S), dan pertanyaan sikap ibu tentang menopause dengan menggunakan skala likert dengan alternative jawaban Sangat Setuju (SS), Setuju (S), Tidak Setuju (TS) dan sangat tidak setuju (STS).

Analisa data yang digunakan dalam penelitian yaitu:Analisis Univariat; Dilakukan terhadap tiap variable dari hasil penelitian dan dianalisis untuk mengetahui distribusi frekuensi dan persentase dari tiap variable. Yaitu kategori pengetahuan dan sikap ibu usia 40-45 tahun tentang menopause. Dan Analisis Bivariat; Analisa hasil penelitian untuk menguji hipotesis menggunakan bantuan program SPSS. Keputusan pengujian hipotesis penelitian dilakukan dengan taraf signifikan $5 \%$ atau alfa $=0,05$ dengan confidence interval $95 \%$ (Rosner, 2000). Uji statistic untuk melihat hubungan antara variable bebas dan terikat digunakan chi square. Adapun untuk melihat analisa bivariat dapat dilihat pada table di bawah ini:

Tabel 1.

Hubungan antara Pengetahuan dengan Sikap terhadap Menopause

\begin{tabular}{|l|l|l|l|}
\hline Sikap & & & \\
Pengetahuan & & - & $\mathrm{N}$ \\
\hline$\uparrow$ & $\mathrm{A}$ & $\mathrm{B}$ & $\mathrm{a}+\mathrm{b}$ \\
\hline$\downarrow$ & $\mathrm{C}$ & $\mathrm{D}$ & $\mathrm{c}+\mathrm{d}$ \\
\hline $\mathrm{N}$ & $\mathrm{a}+\mathrm{c}$ & $\mathrm{b}+\mathrm{d}$ & $\mathrm{a}+\mathrm{b}+\mathrm{c}+\mathrm{d}$ \\
\hline
\end{tabular}

3. HASIL DAN PEMBAHASAN Hasil

Analisis Univariat

Tabel 2.

Distribusi Frekwensi Karakteristik responden Menurut Umur, Tingkat Pendidikan, Pekerjaan, Pernah mendapat informasi, dan macam informasi yang diterima di RW 04 Suka Mulya Wilayah Kerja

Puskesmas Sail Pekanbaru Tahun 2010

\begin{tabular}{|c|l|c|c|}
\hline No & Karakteristik Ibu & N & $\%$ \\
\hline 1 & Umur & & \\
& a. 40 th & 23 & 46 \\
& b. 41 th & 6 & 12 \\
& c. 42 th & 7 & 14 \\
& d. 43 th & 7 & 14 \\
& e. 44 th & 1 & 2 \\
& f. 45 th & 6 & 12 \\
\hline 2 & Pendidikan & & \\
& a. SD-SMP (Rendah) & 10 & 20 \\
& b. SMA (Menengah) & 23 & 46 \\
& c. PT (Tinggi) & 17 & 34 \\
\hline 3 & Pekerjaan & & \\
& a. Bekerja & 17 & 34 \\
& b. Tidak bekerja & 33 & 66 \\
\hline 4 & Pernah mendapat & & \\
& informasi & & \\
& a. Ya & 33 & 66 \\
& b. Tidak & 17 & 34 \\
\hline 5 & Macam informasi & & \\
& a. Petugas kesehatan & 15 & 30 \\
& b. Media elektronik & 18 & 36 \\
& c. Tidak ada & 17 & 34 \\
\hline
\end{tabular}

Sumber: Analisis Data primer,2010

Dari tabel diatas dapat dilihat bahwa kelompok umur responden yang terbanyak adalah umur 40 tahun (46\%). Untuk tingkat pendidikan kelompok responden paling tinggi 
berada pada pendidikan SMA (46\%), untuk pekerjaan responden sebanyak $66 \%$ tidak bekerja atau 33 orang ibu sebagai ibu rumah tangga. Untuk informasi yang pernah diterima oleh responden sebanyak 33 orang atau $66 \%$, ibu-ibu sudah pernah mendapat informasi tentang menopause dimana informasi yang terbanyak didapat dari buku/majalah yaitu $28 \%$ atau 14 orang.

\section{Tabel 2.}

Distribusi Frekwensi Tingkat Pengetahuan Responden Tentang Menopause di RW 04 Suka

Mulya Wilayah Kerja Puskesmas Sail Pekanbaru 2010

\begin{tabular}{|c|c|c|c|}
\hline No & $\begin{array}{c}\text { Tingkat } \\
\text { Pengetahuan }\end{array}$ & F & $\%$ \\
\hline 1 & Tinggi & 33 & 66 \\
2 & Rendah & 17 & 34 \\
\hline & Jumlah & 50 & $100 \%$ \\
\hline
\end{tabular}

Dari tabel 2 dapat dilihat $66 \%$ atau 33 orang ibu mempunyai tingkat pengetahuan tinggi tentang Menopause.

\section{Tabel 3.}

Distribusi Frekwensi Sikap Ibu dalam penanganan memghadapi Menopause di RW 04 Suka Mulya

Wilayah Kerja Puskesmas Sail Pekanbaru 2010

\begin{tabular}{|c|c|c|c|}
\hline No & Sikap & F & $\%)$ \\
\hline 1 & Positif & 29 & 58 \\
2 & Negatif & 21 & 42 \\
\hline & Jumlah & 50 & 100 \\
\hline
\end{tabular}

Sumber: Analisis Data Primer, 2010

Dari tabel 3 dapat dilihat 58\% atau 29 orang ibu mempunyai sikap positif dalam menghadapi menopause

\section{Analisis Bivariat}

Tabel 4.

Hubungan antara pengetahuan dengan Sikap Ibu Tentang Menopause

\begin{tabular}{|l|l|l|l|l|l|l|l|}
\hline \multirow{2}{*}{$\begin{array}{l}\text { Tingkat } \\
\text { Pengetahuan }\end{array}$} & \multicolumn{3}{|l|}{ Sikap } & \multicolumn{2}{|l|}{ Total } & \multirow{2}{*}{\begin{tabular}{l}
$\rho$ \\
\cline { 2 - 7 }
\end{tabular}} & + \\
\cline { 2 - 7 } & $\mathrm{N}$ & $\%$ & $\mathrm{~N}$ & $\%$ & $\mathrm{~N}$ & $\%$ & \\
\hline Tinggi & 21 & 63,6 & 12 & 36,4 & 33 & 100 & \\
\hline Rendah & 8 & 47,1 & 9 & 52,9 & 17 & 100 & \multirow{2}{*}{$\mathrm{O}, 41$} \\
\hline Jumlah & 29 & 58,0 & 21 & 42 & 50 & 100 & \\
\hline
\end{tabular}

Sumber: Analisis Data Primer, 2010

Dari tabel 4. didapatkan $\rho$ value $0,41>\alpha$ 0,05 artinya tidak terdapat hubungan antara pengetahuan dengan sikap ibu usia 40-45 tahun tentang menopause

\section{Pembahasan}

\section{Karakteristik responden}

Gambaran karakteristik responden tentang umur pada penelitian ini dapat dilihat pada tabel 1, dimana dari 50 orang responden terdapat 23 orang atau $46 \%$ responden yang mempunyai umur 40 tahun. Hal ini merupakan suatu pendukung, dimana pada usia ini merupakan suatu usia produktif terhadap peningkatan kualitas pengetahuan.

Gambaran karakteristik responden tentang pendidikan di mana sebanyak 10 orang atau (20\%) mempunyai pendidikan rendah (SDSMP) sedangkan tingkat pendidikan sedang (SMA) sebanyak 23 orang atau $(40 \%)$ dan tingkat pendidikan tinggi (Perguruan Tinggi) sebanyak 17 orang atau (34\%). Hal ini diperkuat oleh Notoatmodjo (2003) mengatakan semakin tinggi pendidikan seseorang maka semakin tinggi pula pengetahuan seseorang tersebut. Hal ini berkaitan dengan sejumlah saluran informasi baik cetak maupun eloktronik yang lebih banyak pada orang yang berpendidikan tinggi sedangkan individu yang berpendidikan rendah bisa saja mempunyai pengetahuan yang lebih tinggi karena mendapatkan ilmu secara otodidak baik secara informal maupun dari pengalaman seharihari (Notoatmojo, 2005).

Gambaran karakteristik responden tentang pekerjaan dimana dari 50 responden sebanyak 33 orang (66\%) tidak bekerja. Walaupun lebih banyak responden yang tidak bekerja dari pada yang bekerja, responden yang memiliki pekerjaan sebagai ibu rumah tangga akan lebih banyak waktu untuk mencari pengetahuan tentang menopause. Menurut Sanjatmiko (2004), mengatakan di dalam lingkungan pekerjaan faktor dominan yang menentukan seperti pola komsumsi nutrisi, proses sosialisasi dan media komunikasi, di mana individu yang tidak bekerja dengan pendidikan rendah akan mengandalkan media siaran dibandingkan dengan individu yang bekerja dengan pendidikan tinggi lebih mengandalkan semua saluran informasi. 
Gambaran karakteristik responden tentang informasi yang diterima tentang menopause dari tabel 4.1, didapatkan bahwa dari 50 responden, 33 orang $(66 \%)$ responden pernah mendapatkan mendengar/ informasi tentang menopause. Sumber informasi yang didapatkan responden diperoleh dari petugas kesehatan, kader, TV/ Radio, buku/ koran. Sumber informasi yang didapatkan dari buku/majalah lebih banyak yaitu sebanyak 14 orang (28\%). Hal ini karena ibu yang bekerja dan berpendidikan tinggi lebih menyukai atau mengandalkan semua saluran informasi terutama media cetak.

\section{Tingkat Pengetahuan Responden}

Tingkat Pengetahuan responden tentang menopause dapat kita lihat pada tabel 2, di mana didapatkan proporsi tingkat pengetahuan tinggi sebanyak 33 orang $(66 \%)$ padahal $40 \%$ responden mempunyai pendidikan menengah (SMA). Peneliti menilai bahwa pengetahuan responden telah mendekati ideal karena $66 \%$ responden telah berpengetahuan tinggi, pernyataan ini diperkuat Notoatmodjo (2003) mengatakan semakin tinggi tingkat pendidikan seseorang maka semakin tinggi pula pengetahuan seseorang tersebut.

Selain itu pengetahuan responden yang tinggi tentang menopause juga dikarenakan responden telah mendapatkan informasi tentang menopause. Hal ini dapat dilihat dari hasil penelitian sebanyak 33 orang (66\%) menyatakan pernah mendapatkan informasi tentang menopause. Pernyataan ini didukung oleh Notoatmodjo (2005), baiknya pengetahuan seseorang dipengaruhi oleh sumber informasi yang diperoleh dari berbagai sumber yang ada, informasi tersebut dapat di peroleh dari penyuluhan, media massa, media cetak, dan elektronik.

Hasil penelitian ini berbeda dengan penelitian Ida (2004) yang berjudul pengetahuan ibu tentang premenopause di RT 03 RW 04 kelurahan Benteng Kota Ambon, pengetahuan responden tentang premenopause sebagian besar dalam kategori kurang (75\%). Ketidaktahuan responden disebabkan karena tidak adanya atau kurangnya informasi yang diterima, mereka berfikir premenopause dan menopause akan dialami oleh semua wanita, jadi tidak penting untuk diketahui.

Tingkat pengetahuan juga berdampak besar dalam perubahan sikap ibu, menurut Notoatmodjo (2003), pengetahuan diperoleh dari berbagai hal, antara lain; pengalaman, ingatan dan kesaksian, minat dan rasa ingin tau, pikiran dan logika serta kebutuhan manusia. Ini berarti tingginya pengetahuan responden tentang menopause disebabkan oleh karena responden merasa hal itu merupakan kebutuhan. Karena jika para ibu premenopause membutuhkan dan berminat untuk mengetahui cara penanggulangan perubahan-perubahan fisiologis pada masa menopause akan sangat cepat dimengerti sehingga tidak ada rasa cemas dan kuatir dalam menghadapinya.

\section{Sikap Responden}

Dari hasil penelitian yang dilakukan, didapatkan 29 orang (58\%) responden dengan sikap positif lebih banyak dibandingkan responden dengan sikap negatif yaitu 21 orang (42\%). Berdasarkan analisis fungsi sikap menurut (teori Katz dalam Notoatmojo 2005), sikap dapat berfungsi sebagai penyesuaian, karena sikap yang diambil oleh seseorang, maka orang akan dapat menyesuaikan diri terhadap sekitarnya, sehingga orang yang bersangkutan mudah diterima oleh kelompoknya. Bila dihubungkan dengan teori Katz tersebut, responden dalam penelitian ini termasuk sebagai kelompok yang mendukung terhadap penanggulangan perubahan-perubahan fisiologis pada masa menopause.

Hal ini sesuai dengan pendapat Notoatmojo (2005), yang menyebutkan bahwa terbentuknya perilaku baru yaitu sikap dimulai dari domain kognitif di mana individu mengetahui terlebih dahulu stimulus berupa materi atau objek di luarnya sehingga menimbulkan pengetahuan baru pada individu yang akan memberikan respon batin dalam bentuk sikap individu terhadap objek yang diketahui. Pengetahuan akan membentuk kepercayaan dan selanjutnya akan memberikan dasar dalam mempersepsikan serta menentukan sikap terhadap objek tertentu. 
Kepercayaan yang dimaksud adalah keyakinan bahwa seseorang benar atau salah atas dasar bukti, sugesti, otoritas, pengalaman dan institusi. Pengetahuan seseorang terhadap sesuatu objek dapat berubah dan berkembang sesuai kemampuan, pengalaman tinggi rendahnya mobilitas materi informasi tentang objek tersebut di lingkungannya (Mochtar, 2005).

Azwar (2003), menyatakan bahwa banyaknya faktor yang mempengaruhi terbentuknya sikap seseorang seperti media masa yang memberikan informasi, pengalaman pribadi, pengaruh orang lain dan lembaga pendidikan yang juga mempunyai pengaruh terhadap pembentukan sikap seseorang. Peneliti berpendapat bahwa sikap responden ini telah mendekati ideal tentang menopause dikarenakan $66 \%$ dari responden berpengetahuan tinggi, pernyataan ini didukung oleh Notoatmodjo (2003) mengatakan hubungan antara tahu dari input mengenai stimulus atau respon datang dari individu, dalam hal ini pengetahuan merupakan stimulus yang membentuk suatu sikap baik yang bersifat positif maupun negatif dipengaruhi oleh pengetahuan.

Hasil penelitian ini berbeda dengan penelitian yang dilakukan oleh Sari (2002) tentang sikap wanita menopause tentang menopause di RT 02 RW 04 kelurahan Rejosari yaitu responden sebagian besar mempunyai sikap negatif sebanyak 29 orang (58\%) dari 50 responden yang diteliti, hal ini disebabkan oleh sebagian besar responden berpendidikan SMP yaitu sebanyak 26 orang (52\%). Jadi walaupun sikap responden dalam kategori positif namun sikap itu dapat berubah-ubah sewaktu-waktu sesuai dengan faktor-faktor yang dapat mempengaruhi sikap seseorang. Oleh karena itu penyuluhan tentang menopause masih harus perlu dilakukan.

\section{Hubungan antara pengetahuan dengan sikap ibu usia 40-45 tahun tentang menopause}

Dari tabel 4 memperlihatkan hasil uji chi square tidak terdapat hubungan yang bermakna antara pengetahuan ibu dengan sikap ibu dimana $\rho=0,41>0,05$. Artinya Ibu yang mempunyai pengetahuan tinggi tentang menopause tidak mempengaruhi sikap ibu untuk bersikap positif maupun negatif karena perbedaan antara pengetahuan tinggi dan rendah yang mempunyai sikap positif dan negatif tidak terlalu signifikan, dengan Ibu yang berpendidikan menegah mempunyai sikap positif $(52,2 \%)$ dan Ibu yang berpendidikan tinggi mempunyai sikap positif (52,9\%). Sedangkan Ibu yang bekerja mempunyai sikap positif $(64,7 \%)$ dan Ibu yang tidak bekerja $(54,5 \%)$.

\section{KESIMPULAN}

Dari hasil penelitian hubungan antara pengetahuan dengan sikap ibu usia 40-45 tahun tentang menopause RW 04 Suka Mulya Wilayah Kerja Puskesmas Sail Pekanbaru yang telah dilakukan pada tanggal 15-17 februari 2010, dapat disimpulkan:

1. Karakteristik responden dari 50 responden sebanyak 23 orang (46\%) berumur 40 tahun, pendidikan responden sebanyak 23 orang $(46 \%)$ berpendidikan sedang (SMA), pekerjaan responden sebanyak 33 orang (66\%) sebagai ibu rumah tangga, sedangkan informasi yang diterima responden sebanyak 33 orang $(66 \%)$ pernah mendapat informasi dimana 14 orang (28\%) mendapat informasi dari majalah / buku.

2. Tingkat pengetahuan responden tentang menopause berada pada tingkat pengetahuan tinggi yaitu sebanyak 33 orang $(66 \%)$.

3. Sikap responden dalam penanggulangan menopause khususnya ibu yang berusia 4045 tahun mempunyai sikap positif 29 orang $(58 \%)$.

4. Dari hasil penelitian menunjukkan bahwa tidak ada hubungan yang signifikan antara tingkat pengetahuan dengan sikap ibu tentang menopause dimana $\rho=0,41$

\section{DAFTAR PUSTAKA}

Atantri, A. 2005. Premenopuse. Diperoleh taggal 08 mei 2009 dari http: // www.bunyu.online.com.masa- pramenopause.html 
Arikunto, S, 2006. Prosedur Penelitian Suatu pendekatan Praktik. Rineka Cipta, Jakarta

Azwar, S. 2002. Sikap manusia Teori Dan Pengukurannya. Pustaka Pelajar, Yogyakarta

Azwar, S. 2003. Sikap Dan Prilaku Manusia. Pustaka Pelajar, Jogyakarta

Aziz, A, 2007. Metode Penelitian Kebidanan dan Teknik Analisa Data. Salemba Medika, Jakarta

Blankast, A. 2008. Mencegah Menopuse Dini. Diperoleh taggal 19 september 2008 dari http:// manik.web.id.html

Depkes, 2008. Menopause. Diperoleh tanggal 20 mei 2009 dari http://Dechare.com.All.Rights.Reserved

DepkesRI, 2005.Terjadi Pergesaran Umur Menopause. Diperoleh tanggal 05 agustus 2008 dari http://www.depkes.go.id/index

Digilib, 2007. Pengertian Menopause. Diperoleh tanggal 01 mei 2009 dari http: // klinikpasutri-blogspot.com.menopauseperempuan.html

Fajar, 2005. Terapi Hormon Di Usia Lanjut. Diperoleh tanggal 29 januari 2009 dari http://www.republika.(online 29 januari 2007)

Fatmawati, R. 2009; Tingkat Pengetahuan Ibu usia 45-59 tahun Tentang Menopuse Di RW 13 Tangkerang Timur Wialyah Kerja Puskesmas Tenayan Raya; $\underline{\text { Skripsi }}$

Groundlund, N.E. 2000. Assesment of student achievement, six edition, Allyn and Bacon. America

Irawaty, 2007. Premenopuse. Diperoleh tanggal 27 Oktober 2008 dari http:// luluvikar in Esai. Tracback.

Isral, 2009. Masa Menopause. Diperoleh tangga 108 mei 2009 dari http:// Blog at Word Press.Com

Ida, 2004. Pengetahuan Ibu Tentang $\begin{array}{llllll}\text { Premenopause Di RT } & 03 & \text { RW } & 04\end{array}$ Kelurahan Benteng Kota Ambon; Skripsi

Kasdu, O. 2002. Kiat Sehat dan Bahagia Di Usia Menopause. Puspa Swara. Jakarta

Keraf, 2001. Ilmu Pengetahuan sebuah tinjauan filosofi. Kanasius. Jakarta
Kesrespo, 2007. Psikologi Wanita. Di peroleh tanggal 01 mei 2007 dari http://Republika

Koblinsky, Timyan, Gay. 2002.The healh of women: A global perspective, westview Press Inc. Boulder, San Francisco and oxford.

Lusiana, A. 2006. Buku Ajar Asuhan Kebidanan. EGC. Jakarta

Medicastro, 2007. Menopause. Diperoleh tanggal 01 mei 2007 dari http:// Pusdinakes.or.id/pd persi.Show $=$ detail news \& kode

Mochtar, 2005. Ilmu Perilaku Dan Teorinya. Salemba Medika. Jakarta

Notoatmodjo, S. 2003. Ilmu Kesehatan Masyarakat. Rineka Cipta. Jakarta

Notoatmodjo, S. 2005. Metodologi Penelitian. Rineka Cipta. Jakarta

Nursalam, 2008. Konsep dan Penerapan Metodologi Penelitian Ilmu Keperawatan. Salemba Medika. Jakarta

Pratikno, A. 2005. Penyebab Menopause. Dsiperoleh tanggal 25 september 2009 dari http://www.sarikata.com

Prawihardjo, S. 2009. Ilmu Kandungan. YBPSP. Jakarta

Purwantyastuti, 2008. Premenopuse. Diperoleh tanggal 27 oktober 2008 dari http://luluvikas wordpress.com

Purnobasuki, 2004. Premenopause. Diperoleh Tanggal 27 okteber 2008 dari http://luluvicar wordpress.com

Prabadani, D. 2007. Hubungan Dukungan Suami dengan Kecemasan Ibu Menghadapi Menopause. Diperoleh tanggal 15oktober 2009 dari http://digilib.ons.ac.id/abstrak.1064

Ridwan.2004. Skala Pengukuran variabel penelitian. Alfabeta. Bandung

Rosner. 2000. Fundamental of biostatistics; fifth edition, Harvad University Press, America

Sunaryo, 2004. Psikologi Untuk Perawat. EGC. Jakarta

Sanjatmiko, P. 2004. Faktor-faktor lingkungan Sosial Budaya Yang Mendukung Proses Menarche Wanita.Diperoleh tanggal 15 maret 2010 dari http:// blog Unes. Ac.id. 
Supardi, S;Pramono, D; Nawi.2000. Statistik Kesehatan. Yogyakarta: UGM

Sari, M. 2002. Sikap wanita menopause Tentang Menopause Di RT 02 RW 04 Kelurahan Rejosari; Skripsi

Wirakusuma, E. 2004. Tetap Sehat, Cantik, dan Bahagia di Masa menopause dengan
Terapi Estrogen Alami. Pustaka Utama. Jakarta.

Yatim, F. 2001.Haid Tidak Wajar dan Menopuse. Pustaka Populer Obor. Jakarta.

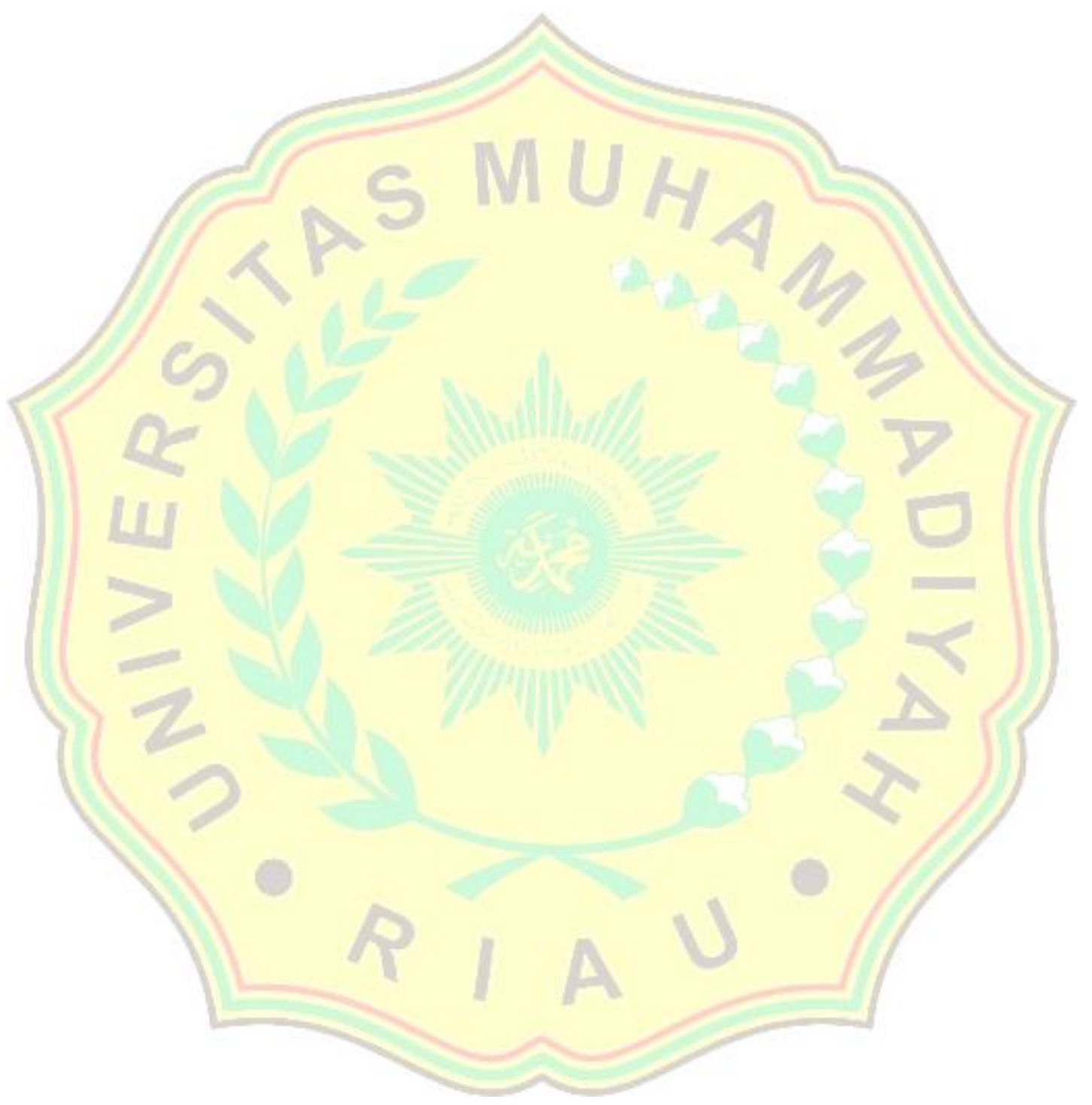

